\title{
PENGUKURAN DIMENSI KOMPONEN ARTIFICIAL HIP JOINT HASIL INVESTMENT CASTING MENGGUNAKAN MATERIAL AISI 316L
}

\author{
Reza Azizul Nasa A.H \\ Teknik Mesin, Fakultas Teknik dan Sains, Studi Teknik Mesin \\ Universitas Muhammadiyah Purwokerto \\ *Email : rezazizul@gmail.com \\ Dwi Purwanto \\ Teknik Mesin, Fakultas Teknik dan Sains, Studi Teknik Mesin \\ Universitas Muhammadiyah Purwokerto \\ *Email : dwi.purwanto.n@gmail.com
}

\begin{abstract}
ABSTRAK
Investment casting merupakan salah satu proses pengecoran yang banyak digunakan untuk proses pembuatan komponen yang rumit. Pembuatan dengan menggunakan proses ini memiliki kelebihan antara lain produk yang dihasilkan dapat mendekati bentuk akhir. Pada tahun 2013 teknik mesin Universitas Diponegoro mulai melakukan penelitian mengenai artificial hip joint. Saat ini proses pembuatan artificial hip joint menggunakan machining proses. Pembuatan artificial hip joint menggunakan proses machining cenderung memerlukan waktu yang cukup lama dan biaya yang mahal. Tujuan utama penelitian ini adalah mendapatkan kebulatan komponen yang diinginkan dengan melakukan proses finishing pada komponen yang dibuat menggunakan investment casting. Material yang digunakan dalam penelitian ini adalah stainless steel 316L. Setelah dilakukan proses pembuatan menggunakan investment casting dilakukan proses finishing untuk menghaluskan bermukaan dan menghasilkan ukuran yang diinginkan. Hasil pengukuran didasarkan pada ASTM F2033-12 dengan tolerasi sebesar $190 \mu \mathrm{m}$ atau $0.19 \mathrm{~mm}$. Hasil pengukuran menunjukkan kebulatan berbeda sebesar $0.12 \mathrm{~mm}$, yang berarti masih sesuai dengan standar yang di tetapkan oleh ASTM F2033-12 yaitu tidak melebihi $0.19 \mathrm{~mm}$.
\end{abstract}

Kata kunci: artificial hip joint, investment casting, stainless steel 316L.

\section{ABSTRACT}

Investment casting is one of casting process that is mostly used for producing a complicated component. The advantage this process is that the result is close to the final shape. In 2013, mechanical engineering Diponegoro University started a research about artificial hip joint. Right now, to make artificial hip joint is used machining process. The process needed a long time and an expensive cost. The objective of the study is to obtain the desired roundness of the components by finishing the components made using investment casting. The materials were used in this study are stainless steel 316L. After the manufacturing process is carried out using investment casting, the finishing process is carried out to smooth the surface and produce the desired size. The measurement results are based on ASTM F2033-12 with a tolerance of $190 \mu \mathrm{m}$ or $0.19 \mathrm{~mm}$. The measurement results show a different roundness of $0.12 \mathrm{~mm}$, which means that it is still in accordance with the standards set by ASTM F2033-12, which does not exceed $0.19 \mathrm{~mm}$.

Keywords: artificial hip joint, investment casting, stainless steel 316L. 


\section{PENDAHULUAN}

Investment casting atau yang dikenal dengan salah satu teknik pengecoran dengan spesifikasi geometri yang hampir mencapai final. Hal inilah yang membuat proses investment casting lebih banyak digunakan dibandingkan dengan teknik pengecoran lain. Masih banyak keuntungan lain yang bisa didapat dari proses investment casting ini, antara lain dapat membuat produk geometri yang rumit dengan tingkat presisi yang baik, dapat menghasilkan permukaan produk yang baik, dan juga dapat menggunakan berbagai jenis material.

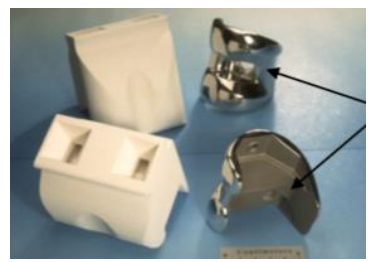

Gambar 1. Knee casting yang terbuat dari cobalt chrome dengan menggunakan cetakan dari keramik [1]

Investment casting merupakan proses penting untuk menghasilkan logam dengan tingkat presisi yang baik seperti kerangka gigi tiruan, mahkota, dan inlay. Proses investment casting harus mendekati bentuk yang sebenarnya. Dengan demikian mold dibuat sedikit melebihi ukuran asli untuk proses permesinan yang dilakukan setelah proses investment casting selesai. Keberhasilan investment casting ditentukan oleh tidak adanya pemuaian yang terjadi pada cetakan saat proses casting berlangsung [2].

Ada 3 tahapan dalam proses investment casting, yaitu produksi wax pattern, produksi mold keramik dan pengecoran logam. Tahap pertama terdiri dari perancangan cetakan untuk wax pattern, proses permesinan dilakukan untuk membuat cetakan kemudian dilakukan proses plactic/wax injection sehingga didapatkan wax pattern. Pada tahap kedua, wax pattern tersebut dicelupkan kedalam ceramic slurry sehingga akan didapatkan lapisan keramik, selanjutkan dilakukan pemanasan sehingga wax bisa meleleh keluar dari lapisan keramik tersebut dan akhirnya didapat mold keramik. Tahap terakhir adalah pengisian logam cair kedalam mold. Sebelum menuangkan logam cair dituang, mold harus dipanaskan terlebih dahulu hinggal suhu $1060^{\circ} \mathrm{C}$ untuk menghindari pecahnya mold saat dituang logam cair. Setelah ditungan spesimen dibiarkan hingga mengeras, lalu mold tersebut dihancurkan untuk mengeluarkan produk. [3].

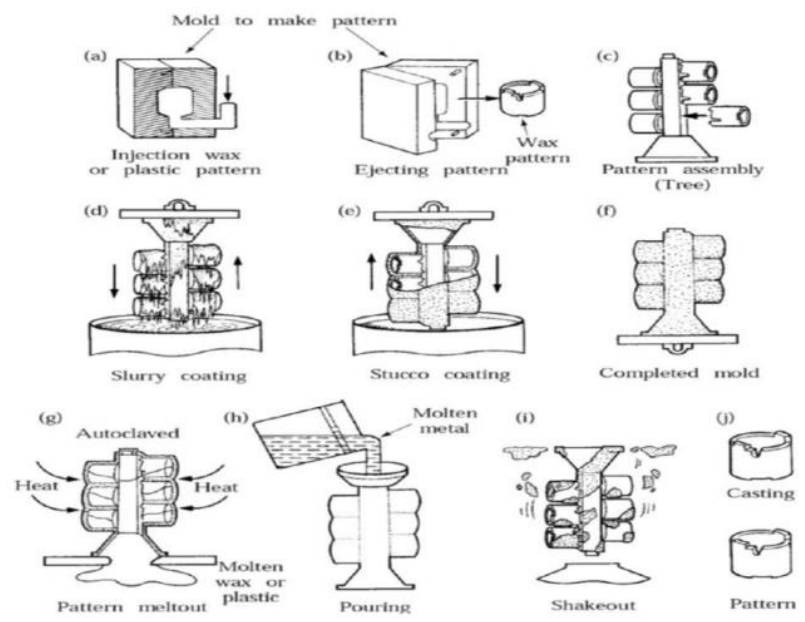

Gambar 2. Proses investment casting [1] 
Proses pembuatan cetakan dilakukan dengan $3 D$ modelling dengan menggunakan software $C A D / C A M$. Pada penelitian ini proses desain mengguakan $C A D / C A M$ merupakan tahap pertama sebelum proses investment casting dilakukan. CAD (Computer Aided Design) digunakan untuk membantu dalam membuat perancangan cetakan untuk wax pattern, lalu CAM (Computer Aided Manufacturing) digunakan untuk membantu perencanaan proses pemesinan cetakan tersebut. [4] Simulasi proses pemesinan dan verifikasi juga dapat dilakukan dengan CAM. Selanjutnya hasil perencanaan yang dilakukan di $C A M$ ini diterjemahkan oleh sebuah post processor agar dapat dijalankan di mesin $\mathrm{CNC}$ tertentu.

\section{METODOLOGI}

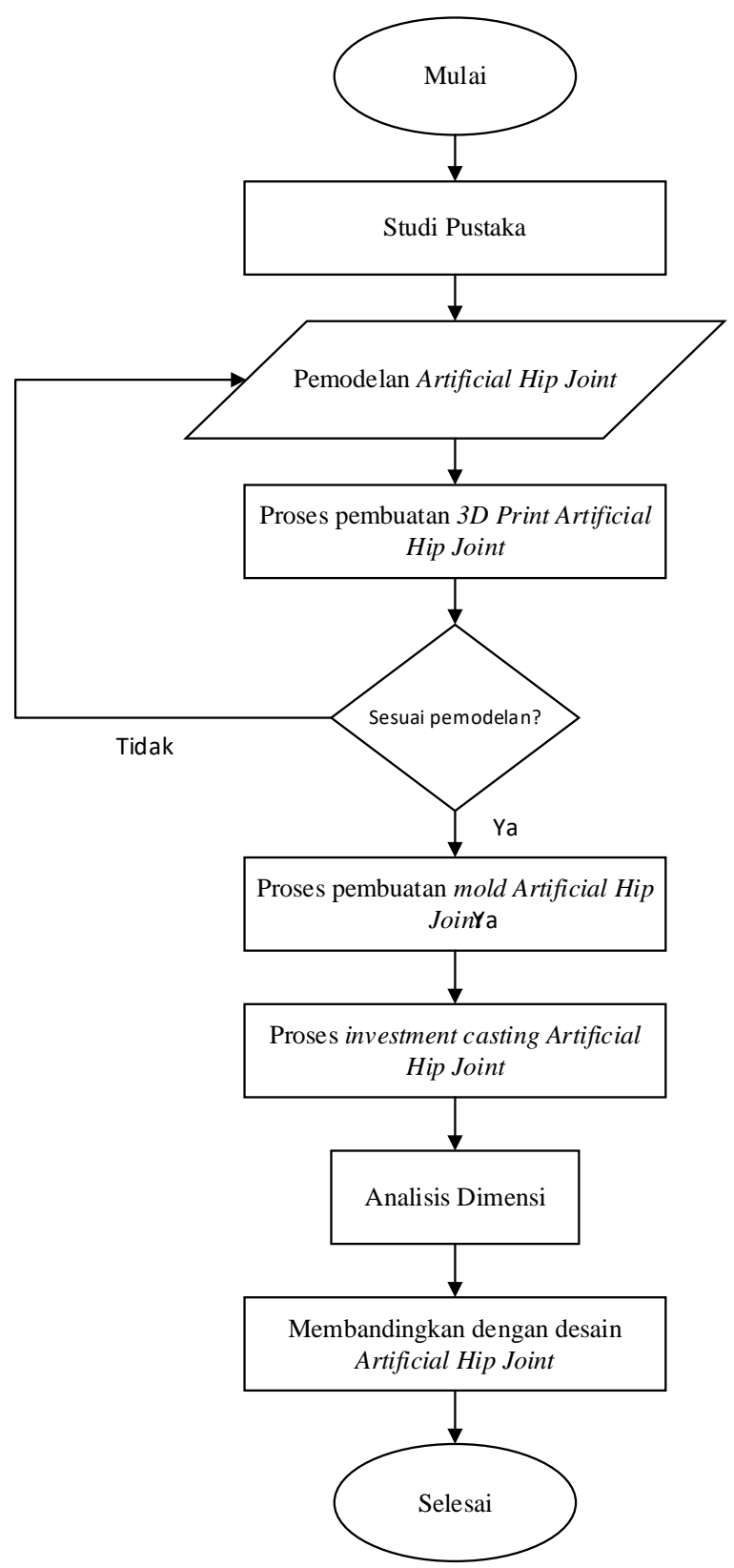

Gambar 3. Diagram alir penelitian 


\subsection{Alat dan Bahan Pembuatan Artificial Hip Joint 2.1.1 AISI 316L}

Material yang digunakan untuk membuat investment casting adalah AISI 316L dengan mengacu pada ASM International. Untuk data material dapat dilihat pada Tabel 1. [5].

Tabel 1. Komposisi kimia AISI 316L [6]

\begin{tabular}{llllllllll}
\hline & C\% & Si \% & Mn\% & P\% & S\% & Cr\% & Ni\% & Mo\% & N\% \\
\hline Min & - & - & - & - & - & 16,00 & 10,00 & 2,00 & - \\
\hline Max & 0,03 & 1,00 & 2,00 & 0,045 & 0,03 & 18,00 & 14,00 & 3,00 & 0,10 \\
\hline
\end{tabular}

\subsubsection{Mold Artificial Hip Joint}

Pembuatan mold menggunakan material duraluminum (paduan alumunium-tembaga). Unsur pembuatan dari duralium itu sendiri adalah 91-95\% alumunium, tembaga 3,8-4,9\%, mangan 0,3$0,9 \%$, magnesium $1,2-1,8 \%$, besi $<0,5 \%$, silikon $<0,5 \%$, seng $<0,25 \%$, titanium $<0,15 \%$, kromium $<0,1 \%$, dan tidak lebih dari $0,15 \%$ merupakan unsur lainnya. Pada Gambar 4 merupakan salah satu contoh molding yang terbuat dari duralium.

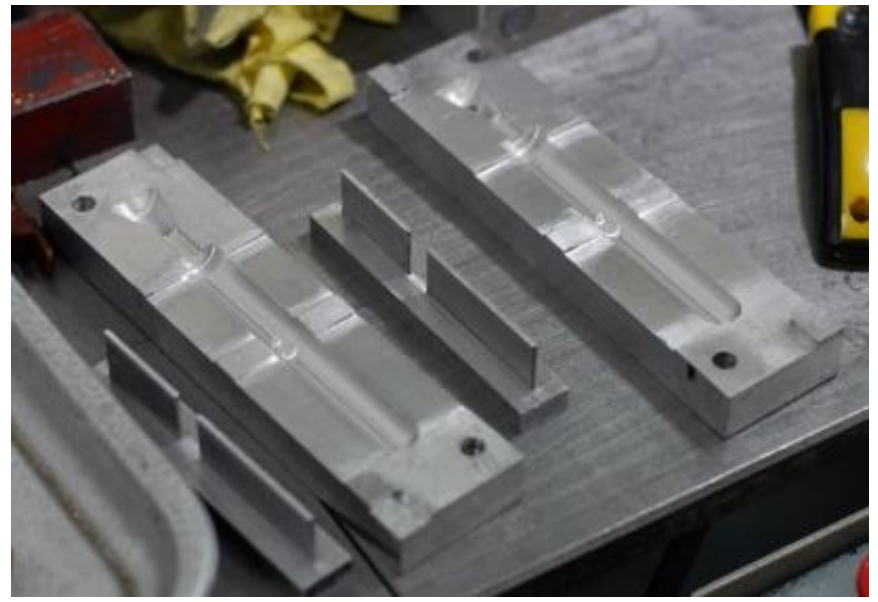

Gambar 4. Mold dengan material duralium

\subsubsection{Prosedur Pembuatan Investment Casting}

Berikut merupakan prosedur pembuatan Investment casting:

1. Penentuan Model

2. Pembuatan Mold

3. Proses injection wax/lilin pada mold

4. Proses pelapisan lilin dengan pasir keramik sebanyak 7 lapis

5. Proses mengeluarkan lilin dari keramik dengan cara memanaskan hingga titik lelehnya.

6. Proses pemanasan cetakan hingga suhu $1060^{\circ} \mathrm{C}$ (untuk menghindari crack saat proses penuangan material).

7. Penuangan AISI $316 \mathrm{~L}$ dan Ti6Al4V pada cetakan.

8. Menunggu spesimen hingga berada pada suhu ruangan/mendingin.

9. Mengeluarkan material dari cetakan dengan cara dipukul menggunakan palu secara perlahan. 


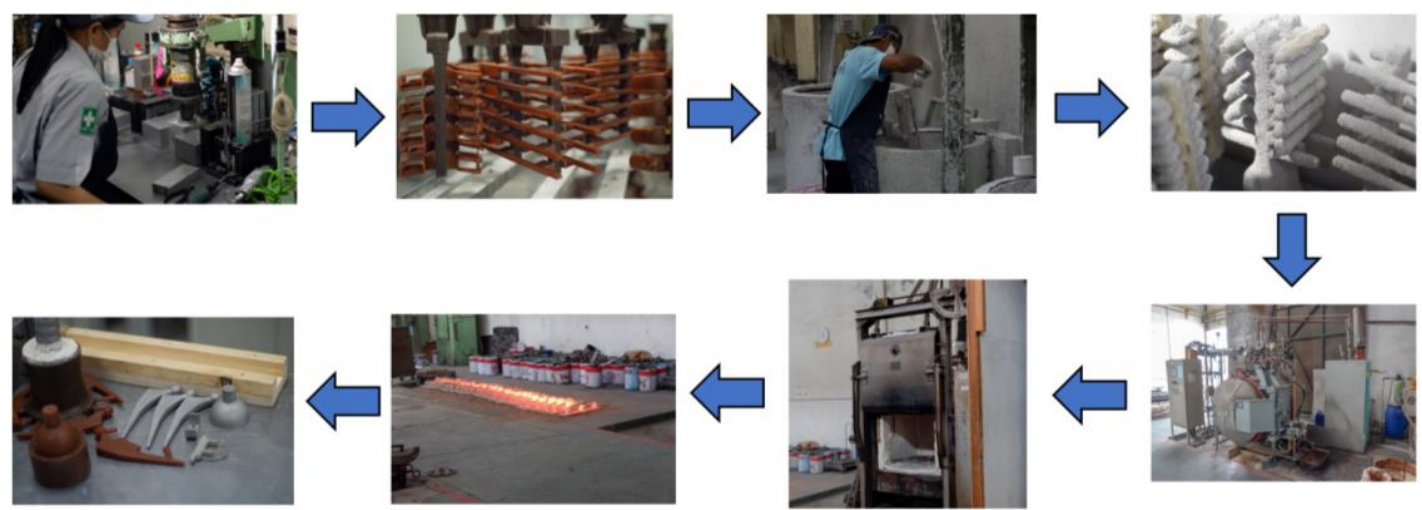

Gambar 5. Proses pembuatan artificial hip joint menggunakan investment casting

\subsection{Pengukuran Dimensi Artifical Hip Joint}

Proses finishing pada komponen artificial hip joint dilakukan di PT. ATMI solo kemudian dilakukan pengukuran di PT. KUBOTA Indonesia semarang menggunakan Mitutoyo Crysta Apex S yang ditunjukkan oleh gambar 6 .

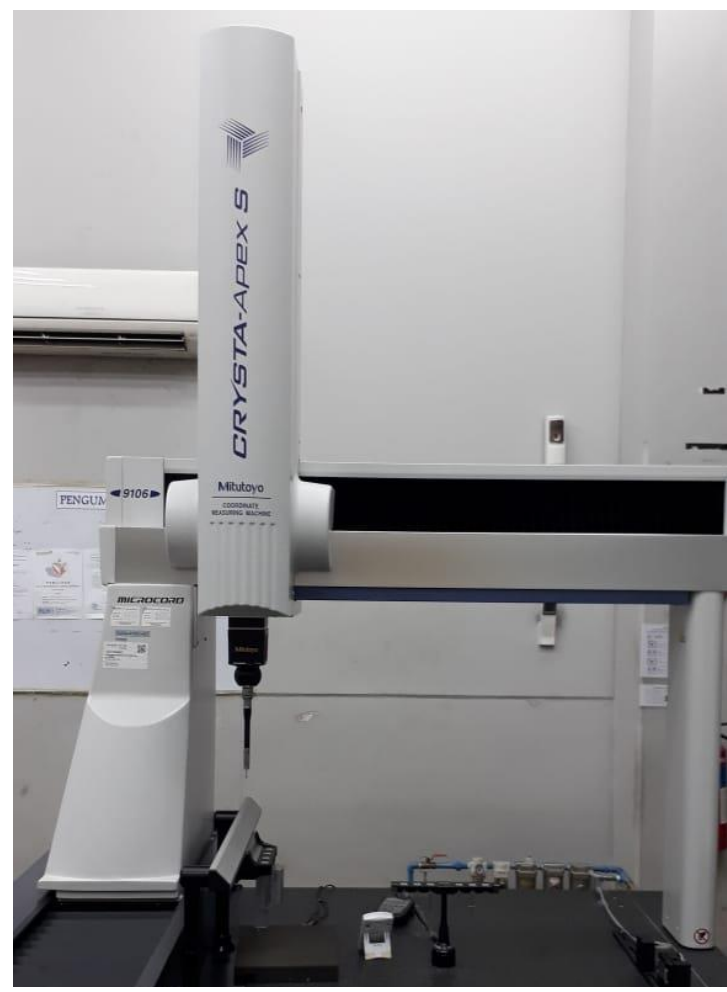

Gambar 6. Mitutoyo Crysta Apex S

\subsection{Desain Artificial Hip Joint Menggunakan Solidworks}

Software yang digunakan untuk mendesain artificial hip joint produk UNDIP pada penelitian ini menggunakan Solidworks 2015 student license [6]. Desain hip joint terdiri dari stem, femoral head, acetabular cup, dan outer liner. Untuk gambar dari setiap komponen dapat dilihat pada Gambar 7. 


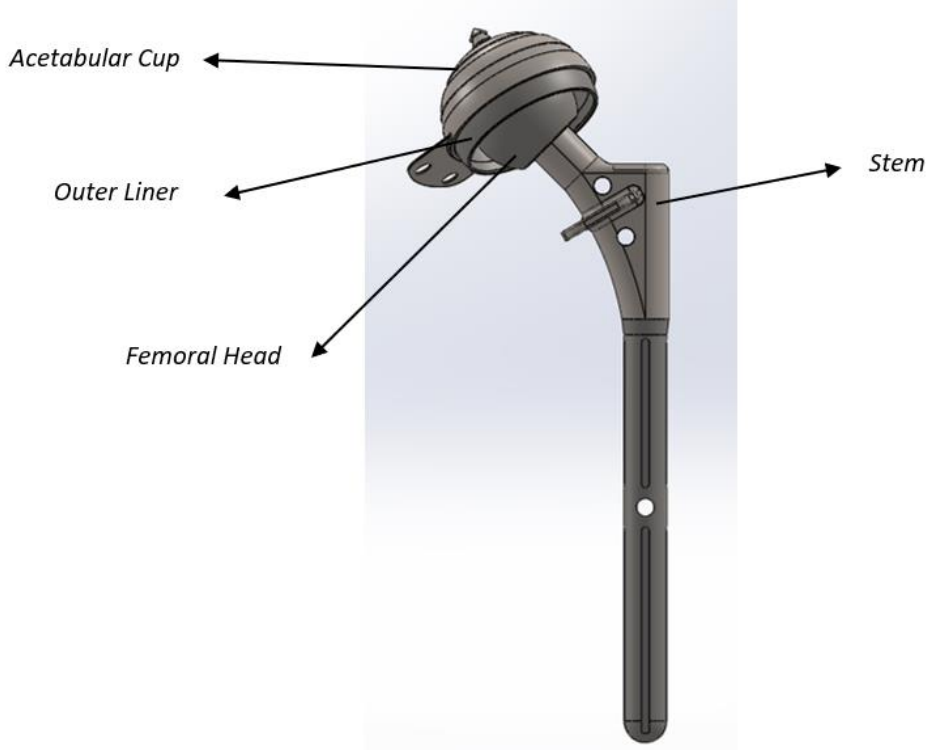

Gambar 7. Desain artificial hip joint menggunakan solidworks

\section{HASIL DAN PEMBAHASAN}

\subsection{Hasil Pengukuran Komponen Artificial Hip Joint}

Berikut ini merupakan hasil pengukuran komponen pada artificial hip joint yang dilakukan pada PT. Kubota Indonesia.

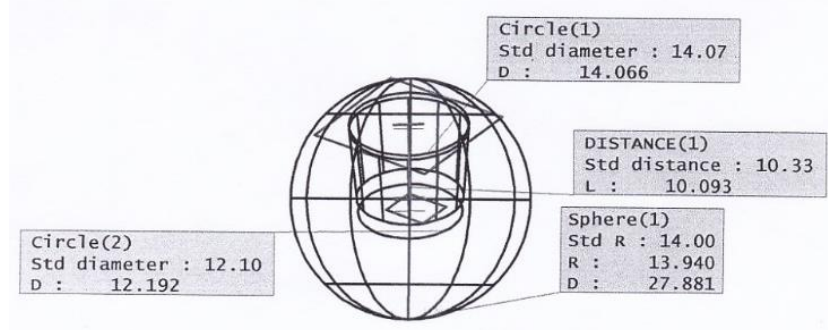

Gambar 8. Hasil pengukuran pada femoral head

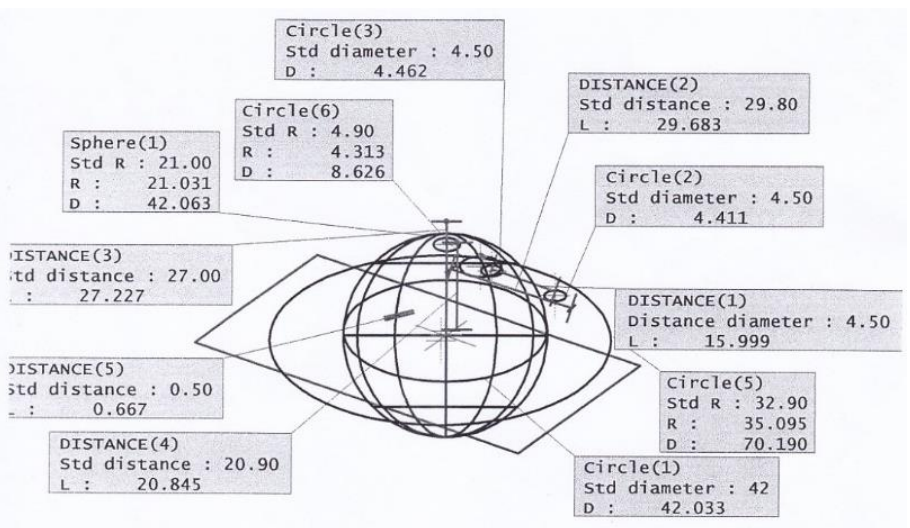

Gambar 9. Hasil pengukuran pada outer liner 


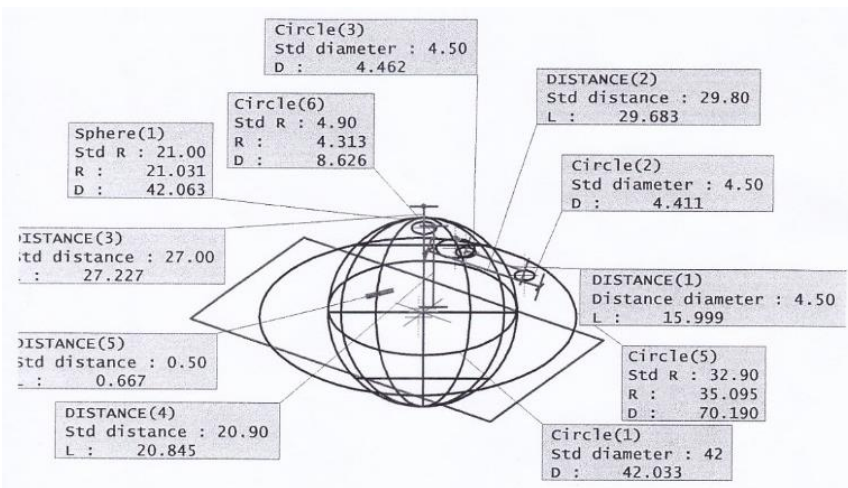

Gambar 10. Hasil pengukuran pada acetabular cup

\subsection{Hasil Pengukuran Komponen Artificial Hip Joint}

Pada gambar 11 sampai 13 menunjukkan hasil pengukuran pada spesimen artificial hip joint hasil investment casting dengan menggunakan AISI 316L.
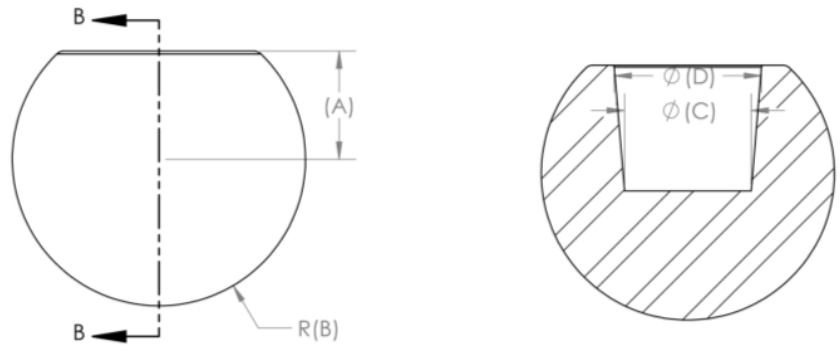

SECTION B-B

Gambar 11. Desain femoral head

Tabel 2. Dimensi acetabular cup

\begin{tabular}{cccc}
\hline & Desain $(\mathbf{m m})$ & Present $(\mathbf{m m})$ & Selisih $(\mathbf{m m})$ \\
\hline A & 10,33 & 10,093 & 0,237 \\
\hline B & 14,00 & 13,940 & 0,06 \\
\hline C & 12,10 & 12,192 & 0,092 \\
\hline D & 14,07 & 14,066 & 0,004 \\
\hline
\end{tabular}
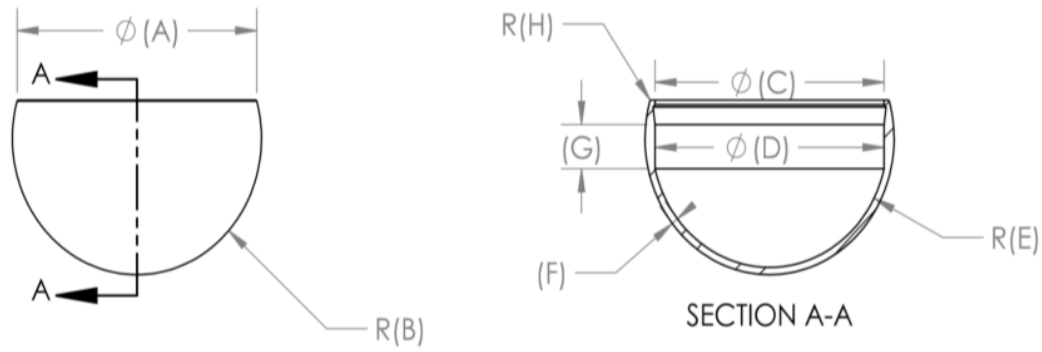

Gambar 12. Desain outer liner 
Tabel 3. Dimensi outer liner

\begin{tabular}{cccc}
\hline & Desain $(\mathbf{m m})$ & Present $(\mathbf{m m})$ & Selisih $(\mathbf{m m})$ \\
\hline A & 37,71 & 38,004 & 0,294 \\
\hline B & 19,60 & 19,441 & 0,159 \\
\hline C & 36,05 & 35,606 & 0,444 \\
\hline D & 36,05 & 35,305 & 0,747 \\
\hline E & 18,55 & 18,103 & 0,447 \\
\hline F & 1,05 & 1,338 & 0,288 \\
\hline G & 6,38 & 6,378 & 0,002 \\
\hline H & 0,20 & 0,162 & 0,038 \\
\hline
\end{tabular}
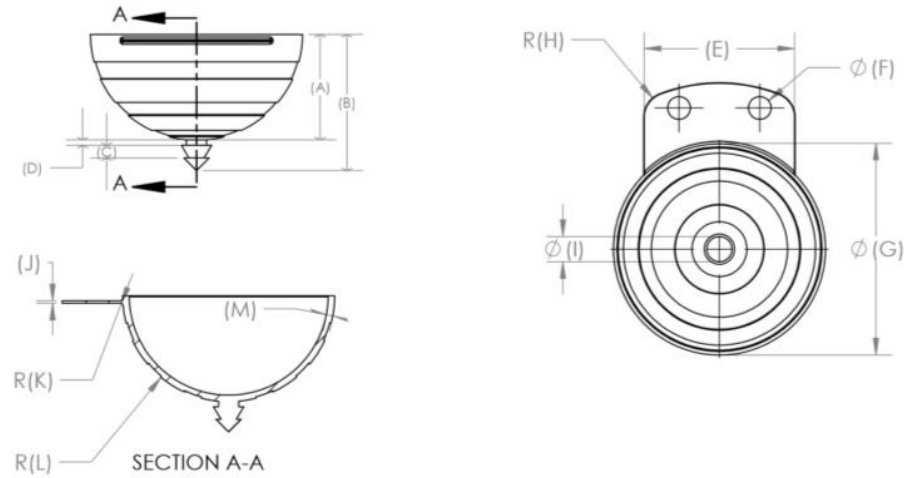

Tabel 4. Dimensi acetabular cup

\begin{tabular}{cccc}
\hline & Desain $(\mathbf{m m})$ & Present $(\mathbf{m m})$ & Selisih $(\mathbf{m m})$ \\
\hline A & 20,90 & 20,845 & 0,055 \\
\hline B & 27,00 & 27,227 & 0,227 \\
\hline C & 2,50 & 2,444 & 0,056 \\
\hline D & 1,10 & 1,168 & 0,068 \\
\hline E & 29,80 & 29,683 & 0,117 \\
\hline F & 4,50 & 4,462 & 0,038 \\
\hline G & 42,00 & 42,033 & 0,033 \\
\hline H & 4,90 & 4,313 & 0,587 \\
\hline I & 5,00 & 4,778 & 0,222 \\
\hline J & 0,50 & 0,667 & 0,167 \\
\hline K & 0,50 & 0,512 & 0,012 \\
\hline L & 21,00 & 21,031 & 0,031 \\
\hline M & 1,30 & 1,370 & 0,07
\end{tabular}

Pada hasil pengukuran material stainless steel $316 \mathrm{~L}$ diatas menunjukkan selisih terbesar terletak pada acetabular cup sebesar 0,587 mm. Selisih yang dihasilkan berdasarkan pengukuran menggunakan mesin Coordinate Measuring Machine (CMM). Adanya selisih diatas disebabkan oleh proses machining. Untuk femoral head ukuran diameter sudah memenuhi ASTM F22033-12 dengan ukuran diameter yang ditentukan yaitu sebesar 28mm - $36 \mathrm{~mm}$. Pada ASTM F2033-12 toleransi maksimum untuk femoral head adalah sebesar $190 \mu \mathrm{m}$ atau $0,19 \mathrm{~mm}$. Pada hasil pengukuran femoral head diameter yang ditentukan adalah sebesar $28 \mathrm{~mm}$ dan hasil pengukuran setelah mengalami proses machining adalah $0,12 \mathrm{~mm}$ sehingga masih sesuai dengan ASTM F2033-12. 


\section{KESIMPULAN}

Produk artificial hip joint hasil proses investment casting menggunakan AISI 316L memiliki hasil akhir yang hampir menyerupai dengan bentuk desain awal menggunakan solidworks setelah melaluli finishing dan dilakukan proses pengukuran menggunakan alat pengukur kebulatan (Mitutoyo Crysta Apex S) di Kubota. Hasil pengukuran kebulatan masih sesuai toleransi yang ditetapkan oleh standar ASTM F2033-12 yaitu tidak melebihi 0.19mm dari desain awal.

\section{DAFTAR PUSTAKA}

[1] Singh, S. and Singh, R. (2017). Investment Casting (Disposable Mold), Reference Module in Material Science and Material Engineering

[2] Darvel B.W. (2018). Materials science for dentistry, Woodhead publishing.

[3] Jones, S. and Yuan, C., 2003. "Advances in shell moulding for investment casting". Journal of Materials Processing Technology 135. 2-3, pp.258-265.

[4] Kennard, R.W. and Stone, L.A., 1969. "Computer aided design of experiments". Technometrics, 11. 1, pp.137-148.

[5] Respati, S.M.B. 2010. "Bahan biomaterial stainless steel dan keramik"..MAJALAH ILMIAH MOMENTUM, 6. 1.

[6] ASM International. [Online]. Available: http://asm.matweb.com

[7] Jamari, J., Ismail, R., Saputra, E., Sugiyanto, S. and Anwar, I.B. 2014. "The effect of repeated impingement on UHMWPE material in artificial hip joint during salat activities". In Advanced Materials Research 896, pp. 272-275 